\title{
Evaluation of the profile of inflammatory cytokines, through immunohistochemistry, in the skin of patients with allergic contact dermatitis to nickel in the acute and chronic phases ${ }^{*}$
}

\author{
Marilene Chaves Silvestre', Vitor Manoel Silva dos Reis ${ }^{2}$
}

DOI: http:/ / dx.doi.org/10.1590/abd1806-4841.20187126

\begin{abstract}
BACKGROUND: Allergic contact dermatitis to ion nickel (Ni+2) is an inflammatory dermatosis, common in industrialized countries. It involves the activation of nickel-specific T-cells, followed by proliferation and induction of a mixed profile of both proinflammatory and regulatory cytokines, suggesting that several T-cell subtypes (helper - Th and cytotoxic - Tc) are involved. A broader understanding of the cytokine profile may lead to new therapeutic approaches.

ОвлестіVEs: This study aimed to analyze the cytokines TNF- $\alpha$, INF- $\gamma$, IL-2, IL-4, IL-10, IL-13, IL-17 and IL-23 using the immunohistochemistry technique in order to try to identify their prevalence in chronic and acute eczema of patients with allergic contact dermatitis to $\mathrm{Ni}+2$.

Methods: We performed an immunohistochemical study for eight cytokines in 20 patients with Ni+2 allergic contact dermatitis, biopsied at the site of chronic eczema, triggered by the patient's daily contact with $\mathrm{Ni}+2$, and at the site of acute eczema caused by nickel sulfate, 48 hours after applying the contact test.

RESULTS: The stained samples showed positive results for the eight cytokines studied. TNF- $\alpha$, IFN- $\gamma$, IL-4, IL-13 and IL-17 had a higher prevalence in chronic eczema, IL-2 and IL-23 in acute eczema, and IL-10 presented a similar prevalence in both acute and chronic eczema. However, these prevalences were statistically significant only for IL-4 and IL-13.
\end{abstract}

Study Limitations: Small sample size.

CONCLUSIONS: In chronic and acute eczema, we observed the presence of a mixed cytokine profile of the T cell subtypes (Th/ Tc), suggesting that the responses are expressed at the same time.

Keywords: Allergy and immunology; Cytokines; Dermatitis, allergic contact; Dermatitis, contact; Immunohistochemistry; Nickel

\section{INTRODUCTION}

Contact dermatitis is a frequent inflammatory condition in industrialized countries, with great socioeconomic impact, being one of the most common occupational diseases, mainly in its irritant form. Among the allergic contact dermatites (ACD), those caused by the ion nickel (Ni2+) affect a large part of the general population..$^{1,2}$

$\mathrm{ACD}$ results from the immune activation in persons previously sensitized, leading to the development of effector T-cells specific to the antigen, which are mediators of the cutaneous inflammation, causing tissue injury. ${ }^{3-5}$

It is difficult to prevent exposure to $\mathrm{Ni} 2+$ since it is present in many common objects for daily use, such as clothing ornaments, jewelry, keys, coins, household utensils, cosmetics, mobile phones, among others. ${ }^{6}$
$\mathrm{Ni2}+$ penetrates the skin and activates epithelial cells that produce cytokines and chemokines. Afterwards, there are hyper-reactive immune responses that involve the activation of T-cells and antigen-presenting cells (APCs), such as cutaneous dendritic cells (DCs) ${ }^{7-9}$ whose main role is to recognize and process external antigens and migrate to the draining lymph nodes (dLNs). ${ }^{3,4}$ Such process gives rise to antigen-specific $\mathrm{T}-\mathrm{CD} 8+$ and $\mathrm{CD} 4+$, differentiating into effectors Thelper 1 (Th1), T helper 17 (Th17) and cytotoxic T lymphocytes (CTLs). ${ }^{3,10,11}$ At the same time, regulatory T-CD4+ cells (Tregs), secreting IL-10 develop, inhibiting ACD's inflammatory process and mediating tolerance in non-allergic individuals. ${ }^{12-14}$ Contact allergy is the result of the interaction between environment exposures and individual susceptibility, and only a fraction of the

\footnotetext{
Received 17 March 2017.

Accepted 18 July 2017 Brazil..

Financial support: None.

Conflict of interest: None.

Department of Tropical Medicine and Dermatology, Universidade Federal de Goiás, Goiânia (GO), Brazil. Department of Dermatology, Faculdade de Medicina, Universidade de São Paulo, São Paulo (SP), Brazil.
}

* Work conducted at Faculdade de Medicina, Universidade de São Paulo, São Paulo (SP); and Hospital das Clínicas, Universidade Federal de Goiás, Goiás (GO),

MAILING ADDRESS:

Marilene Chaves Silvestre

E-mail: marilene.silvestre@terra.com.br 
individuals exposed will become sensitized. The clinical signs of ACD inflammation develop with subsequent exposures.,15

The analysis of cytokine production by Ni2+-specific T-cells demonstrated a mixed profile of cytokines. ${ }^{16}$ In vitro response to $\mathrm{Ni2}+$ was demonstrated involving the activation of $\mathrm{Ni2}+$-specific T-cells, followed by the proliferation and induction of Th1/Tc1 (IL2 and IFN- $\gamma$ ), Th2 (IL-4, IL-5, IL-9 and IL-13), Th17/Tc17 (IL-17A, IL-17F, IL-21, IL-22 and IL-26) cytokines and regulatory cytokines such as IL-10, in the peripheral blood. ${ }^{16-18}$ The stimulus for the differentiation of Th17 cells occurs through pro-inflammatory cytokines such as IL-23, secreted by DCs and macrophages, that stimulate and maintain the production of IL-17, IL- 6 and TNF- $\alpha$. TNF- $\alpha$ can be secreted by activated macrophages, keratinocytes, $\mathrm{T}$ lymphocytes and NK (Natural Killer) or monocytes. It is capable of causing keratinocyte apoptosis and has a pro-inflammatory effect. ${ }^{18,19}$

The objective of this study was to study the cytokines acting on Ni2+ ACD using the immunohistochemistry technique to try to identify its prevalence both in chronic eczema triggered by the daily contact of the patient with $\mathrm{Ni2}+$ and the acute eczema triggered by contact tests (CT) with nickel sulfate (NiSO4).

\section{METHODS}

The research was an observational, uncontrolled, prospective, non-randomized and nonblinded, conducted from 2013 to 2016. Twenty patients with chronic eczema and past history of Ni2+ ACD were assessed. The group analyzed was selected from April 2013 to April 2014 and comprised 17 women and 3 men, between 22 and 75 years of age (median age of 46 years). The study was approved by the Committee of Ethics in Research of the Hospital das Clínicas, Universidade Federal de Goiás - UFG (protocol CAAE 01330712.8.0000.5078).

The patients should fulfill the following criteria to be included: have chronic eczema to Ni2+ in any part of the body; be male or female; be older than 18 years; have chronic eczema to Ni2+ in areas other than the area of application of the contact test (back); have no cutaneous lesions on the back (inflammatory or non-inflammatory); have not used topical or systemic steroids up to 3 weeks before the application of the CT and have not exposed the back to the sun for up to 2 weeks before the application of the CT; and have no history of atopy (chronic pruritus, rhinitis, asthma and family history of atopy). The exclusion criteria considered: any adverse event (any unfavorable sign or symptom) after application of the CT; removal of the CT earlier than 48 hours after its application; CTs that got wet; active phase of ACD; pregnant women and those breastfeeding; refusal of the patient in removing the hairs of the back, when necessary; a patient who was unsure of having a CT, even after signing the consent form.

Contact tests were performed using the Brazilian Standard Series, Patchkit Standard New Generation $®$ (standardized by the Grupo Brasileiro de Estudo em Dermatite de Contato (GBEDC)), comprised of 30 substances allocated into strips (Finn Chamber ${ }^{\circledR}$ aluminum chambers (Epitest Ltd, Finland)) and applied onto healthy skin on the back of the patients. ${ }^{20}$ The patient returned after 48 hours, when the CT was removed and the first reading was performed. After 96 hours the second reading was performed, being the preparation, application, and both readings performed by a single examiner. Reading criteria adopted were those defined by the International Contact Dermatitis Research Group (ICDRG): negative (-); doubtful (?); weak positive (+), light erythema with some papules; strong positive $(++)$, erythema, papules and vesicles; extreme $(+++)$, intense erythema, papules and coalescing vesicles. ${ }^{21,22}$

Two skin biopsies were taken from each of the 20 patients: the first from the area of chronic eczema to Ni2+, before applying the $\mathrm{CT}$; and the second from the area of the acute eczema triggered by $\mathrm{CT}$ with $\mathrm{NiSO} 4,48$ hours after its application with the readings strong positive $(++)$ or extreme $(+++)$. The samples were preserved in formaldehyde and sent to the laboratory. The tissue sections were placed on microscopy slides and the control tissue was placed on the same slide to validate the reaction and maintain quality standards.

Immunohistochemistry was performed for the following cytokines: tumor necrosis factor alpha (TNF- $\alpha$ ), interferon gamma (INF- $\gamma$ ) and interleukins (IL-2, IL-4, IL-10, IL-13, IL-17 and IL-23) in 160 slides of acute eczema and 160 slides of chronic eczema, with a total of 320 slides.

Immunohistochemistry titers were standardized from the references indicated on the labels of the reagents and were diluted (increasing or decreasing concentration) until they reached a clearer pattern. The staining steps consisted in: washing with buffer; endogenous peroxidase blockage (to activate enzymes present in the tissue/cell, that could react with another substrate and interfere with the reaction); washing with buffer; protein blockage (applies only to IL-10) to reduce background staining; primary antibody: dilution with background reducing diluent specific for each antibody (IL-2 1:500, IL-4 1:1000, IL-10 1:15000, IL-13 1:800, IL-17 1:100, IL-23 1:100, IFN- $\gamma$ 1:500 and TNF- $\alpha$ was diluted in BSA $1 \%$ ); washing with buffer; linker (applied for IL-4, IL-13, IL-17 and IL-23): secondary reagent that amplifies the signal of the primary antibody; washing with buffer; polymer: reagent that allowed linking of up to 20 antibody molecules per base structure; washing with buffer; chromogenic substrate: DAB (diaminobenzidine) generated a bright-brown end product on the area of the target antigen; washing with distilled water and buffer; counterstaining: hematoxylin, reagent of histological staining to visualize nuclei in tissue sections and cell preparations; washing with distilled water, buffer and distilled water. ${ }^{23,24}$

The samples were analyzed quantitatively, considering the area of eight fields (papillary/upper dermis) photographed with a photomicroscope with a $x 40$ magnification. The camera AxioCam MR3 and the program AxioVision 4.8 were used, attached to a Zeiss microscope with a $x 40$ magnification. The immunomarked area was measured by the color intensity of the immunohistochemistry reaction with the program Image ProPlus 4. Data obtained were tabulated in a Microsoft Excel 2007 spreadsheet, and the immunomarked area was compared to the area studied in the fields, and a relationship in percentages between the areas was obtained.

Statistical analyses were performed using the statistics software STATA version 13. Cytokines displayed an asymmetrical probability distribution and the median was the best indicator to summarize the data. Methodologies used were Shapiro-Wilks test to evaluate if the data came from a normal probability distribution and the non-parametric test of Mann-Whitney verified if the prevalences 
were similar among chronic and acute eczemas by comparing their medians..$^{25-27}$ The level of significance applied for the tests was of 0.05 .

\section{RESULTS}

The study was conducted using immunohistochemistry for eight cytokines in 20 cases of Ni2+ ACD, both in the samples of chronic eczema, triggered by the daily contact of the patient with $\mathrm{Ni} 2+$, and acute eczema, after 48 hours of the application of the $\mathrm{CT}$. only three slides were excluded for some technical error. The marked samples were positive for cytokines TNF- $\alpha$, INF- $\gamma$, IL-2, IL4, IL-10, IL-13, IL-17 and IL-23 (Figure 1 and Table 1).

The cytokines studied showed heterogeneous values demonstrated by the coefficient of variation (CV), that indicated the variability of the group of data obtained. The main descriptive statistics for each cytokine according to the type of eczema are shown in table 2.

TNF- $\alpha$ had a higher prevalence in chronic eczema (medi$\mathrm{an}=0.97$ ), when compared to acute eczema (median=0.20), being the most prevalent cytokine in chronic eczema (Table 2). There was a higher heterogeneity of values for acute eczema $(\mathrm{CV}=1.34)$, when compared to chronic $(\mathrm{CV}=0.94)$, with the absence of atypical values (Figure 2 and Table 2).

IFN- $\gamma$ prevalence was higher in chronic eczema (median=0.33), when compared to acute eczema (median=0.12) (Table 2). The heterogeneity of the values was higher in acute eczema $(\mathrm{CV}=1.78)$, with the presence of three atypical values (Figure 2 and Table 2).

IL-2 showed a higher prevalence in acute eczema (medi$\mathrm{an}=0.40$ ) than in chronic (median=0.32), being the most prevalence cytokine in acute eczema (Table 2). A higher heterogeneity of the values in acute eczema was also observed $(\mathrm{CV}=1.10)$, with the presence of one atypical value (Figure 2 and Table 2).

There was a higher prevalence of IL- 4 in chronic eczema (median=0.28), when compared to acute eczema (median=0.04) (Table 2). In regard to the heterogeneity of the values, it was higher in in acute eczema ( $\mathrm{CV}=1.97)$, with four atypical values (Figure 2 and Table 2).

IL-10 had a similar prevalence, both in acute and chronic eczema (median=0.01) (Table 2). The heterogeneity of the values was higher in acute eczema $(\mathrm{CV}=2.23)$, with the presence of two atypical values (Figure 2 and Table 2).

IL-13 had a higher prevalence in chronic eczema (median $=0.08$ ) and in acute eczema, the estimated prevalence was very low, near zero (median=0.00) (Table 2). However, there was a higher heterogeneity of the values in acute eczema $(\mathrm{CV}=3.01)$, with the presence of three atypical values (Figure 2 and Table 2).

IL-17 prevalence was higher in chronic eczema (medi$\mathrm{an}=0.19$ ) than in acute (median=0.13) (Table 2). The higher heterogeneity of the values was in acute eczema $(\mathrm{CV}=2.55)$, with two atypical values (Figure 2 and Table 2).

IL-23 had a higher prevalence in acute eczema (median=0.10), when compared to chronic eczema (median=0.09) (Table 2 ). There was also a higher heterogeneity of the values in acute eczema (CV=3.33), with two atypical values (Figure 2 and Table 2).

In the comparison between the medians to verify if the prevalence of each cytokine was similar in chronic and acute eczemas, we observed that, statistically and for a significance level of 0.05 (p-value $<0.05)$, IL-4 (p-value $<0.03)$ and IL-13 (p-value<0.03) me- dians were different in chronic and acute eczemas. However, it was not possible to establish any differences in the values of the medians for the cytokines IFN- $\gamma$, IL-2, IL-10, IL-17, IL-23 and TNF- $\alpha$ (Table 3).

\section{DISCUSSION}

Cytokines are important determinants and modulators in immunological conditions, suggesting a central role of antigen-specific cytokines in ACD. In particular, those types secreted by specific $\mathrm{Ni2}+\mathrm{T}$-cells control the expression of ACD to Ni2+. ${ }^{28}$ The cytokine pattern generated can vary, depending on the specific Ni2+ T-cell clones involved in the inflammatory reaction. ${ }^{29}$ Studies demonstrated that, in the skin with contact eczema, there are differences in the cytokine profile according to the timeline of occurrence of the many participating T-cells. ${ }^{30}$

In our study, TNF- $\alpha$ was more prevalent in chronic eczema than in acute eczema, being the most prevalent cytokine in chronic eczema as a consequence of the persistent inflammation that progresses to chronicity after repeat contact with Ni2+. However, this
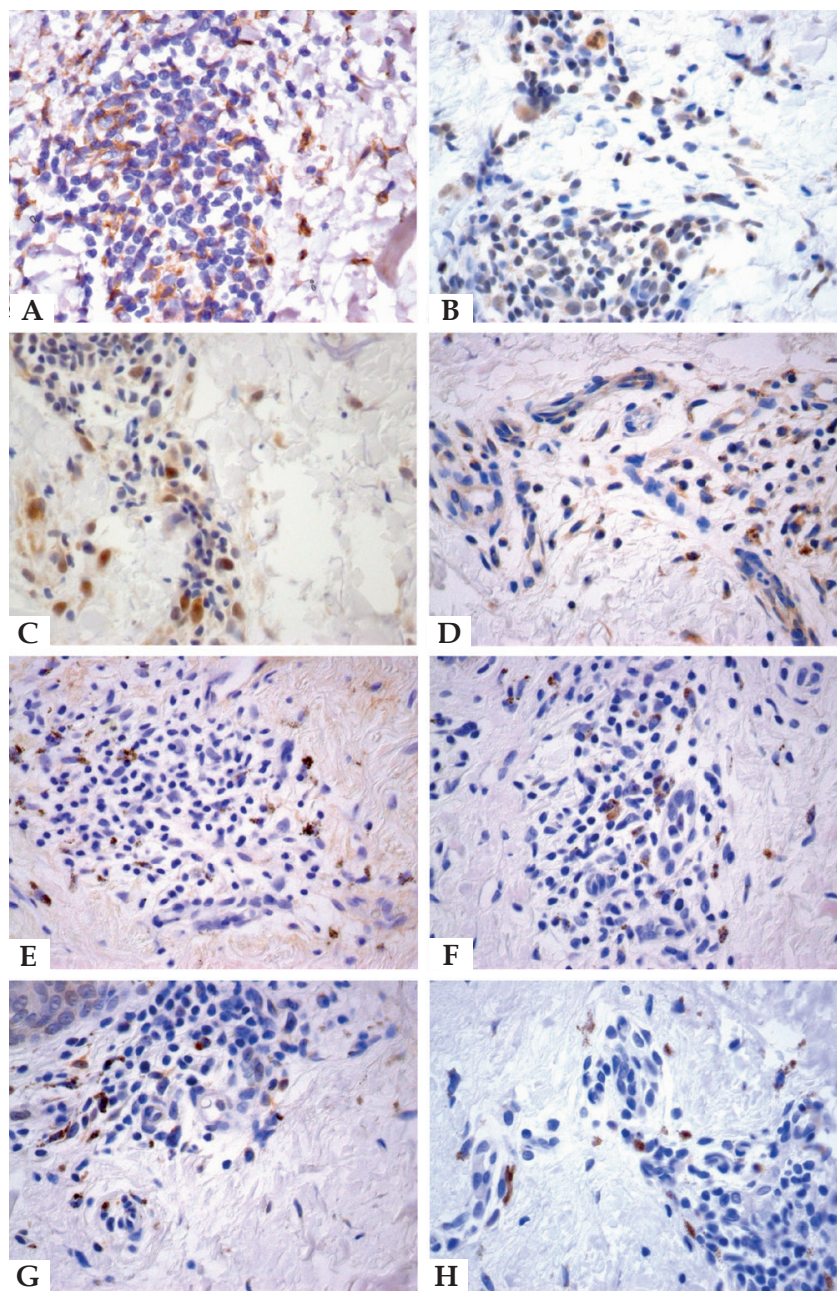

FIGURE 1: Immunohistochemistry. The stained samples showed yielded results. A - TNF- $\alpha$, chronic eczema; $\mathbf{B}$ - INF- $\gamma$, chronic eczema; C - IL-2, acute eczema; D - IL-4, chronic eczema; E - IL-10, chronic eczema; F - IL-13, chronic eczema; G - IL-17, chronic eczema and H - IL-23, acute eczema. Stain: DAB; counterstain: Hematoxylin $(\mathrm{x} 400)$ 
higher prevalence in chronic eczema was not statistically significant. TNF- $\alpha$ produced mainly by macrophages but keratinocytes, monocytes, neutrophils, T lymphocytes and NK cells also produce it. It has anti-inflammatory properties and can be associated to allergic and irritant contact dermatitis. ${ }^{19,31}$ In the elicitation phase of ACD, TNF- $\alpha$ induces keratinocyte apoptosis and activates vascular endothelial cells in order for them to express adhesion molecules such as ICAM-1 and P-/E-selectin, which guide T-cells in the blood to migrate into tissues, contributing to the local inflammatory process caused by $\mathrm{Ni} 2+., 32$
Our data demonstrate that IL-2 had a higher prevalence in acute eczema than in chronic, being the most prevalent cytokine in acute eczema in the biopsy taken 48 hours after provocation with NiSO4. However, this higher prevalence in acute eczema was not statistically significant. There are reports in the literature that IL-2 is a cytokine released in the initial phase of the immune response in patients allergic to $\mathrm{Ni2}+$ and suggestions of positive correlations between the production of IL-2 and the severity of the cutaneous inflammation. ${ }^{29,33}$ Studies in stimulated mononuclear cell cultures in the peripheral blood of patients allergic to Ni2+ yielded significant

TABLE 1: Quantitative analysis of immunohistochemistry reactions for eight cytokines (IFN- $\gamma$, IL-2, IL-4, IL-10, IL-13, IL-17, IL-23 and TNF- $\alpha$ ), in 320 slides (160 of chronic eczema and 160 of acute eczema, caused by nickel) - 2013 to 2016

\begin{tabular}{|c|c|c|c|c|c|c|c|c|c|}
\hline $\mathbf{N}$ & Type of eczema & IFN- $\gamma$ & IL-2 & IL-4 & IL-10 & IL-13 & IL-17 & IL-23 & TNF $-\alpha$ \\
\hline \multirow[t]{2}{*}{1} & Chr eczema & $0.737 \%$ & $0.950 \%$ & $0.21736 \%$ & $0.0000 \%$ & $0.32880 \%$ & $0.2097 \%$ & $0.0506 \%$ & $0.0000 \%$ \\
\hline & Ac eczema & $0.468 \%$ & $0.356 \%$ & $0.11655 \%$ & $0.0000 \%$ & $0.01192 \%$ & $0.3323 \%$ & $0.1853 \%$ & $0.1880 \%$ \\
\hline \multirow[t]{2}{*}{2} & Chr eczema & $0.534 \%$ & $0.342 \%$ & $3.13765 \%$ & $0.0040 \%$ & $0.04453 \%$ & $1.1653 \%$ & $0.1693 \%$ & $0.0000 \%$ \\
\hline & Ac eczema & $3.952 \%$ & $0.819 \%$ & $3.20573 \%$ & $0.0378 \%$ & $0.84125 \%$ & $5.6904 \%$ & $0.4186 \%$ & $0.3678 \%$ \\
\hline \multirow[t]{2}{*}{3} & Chr eczema & $0.108 \%$ & $1.452 \%$ & $0.32544 \%$ & $0.0000 \%$ & $0.00000 \%$ & $0.0770 \%$ & $0.0006 \%$ & $0.9725 \%$ \\
\hline & Ac eczema & $0.451 \%$ & $1.755 \%$ & $3.59343 \%$ & $0.0000 \%$ & $0.00000 \%$ & $0.2111 \%$ & $0.0664 \%$ & $0.0000 \%$ \\
\hline \multirow[t]{2}{*}{4} & Chr eczema & $0.059 \%$ & $0.032 \%$ & $0.44645 \%$ & $0.0000 \%$ & $0.0000 \%$ & $0.1743 \%$ & $0.0000 \%$ & $0.0000 \%$ \\
\hline & Ac eczema & $0.546 \%$ & $0.771 \%$ & $0.0000 \%$ & $0.0000 \%$ & $0.08509 \%$ & $0.5510 \%$ & $0.0327 \%$ & $1.6624 \%$ \\
\hline \multirow[t]{2}{*}{5} & Chr eczema & $0.607 \%$ & $0.909 \%$ & $0.19518 \%$ & $0.4680 \%$ & $0.22678 \%$ & $0.1789 \%$ & $0.2823 \%$ & $0.6662 \%$ \\
\hline & Ac eczema & $0.882 \%$ & $1.682 \%$ & $0.04640 \%$ & $0.0000 \%$ & $0.00074 \%$ & $0.7116 \%$ & $0.4925 \%$ & $2.1741 \%$ \\
\hline \multirow[t]{2}{*}{6} & Chr eczema & $0.604 \%$ & $1.104 \%$ & $1.61041 \%$ & $0.3669 \%$ & $0.44522 \%$ & $0.7280 \%$ & $0.4121 \%$ & $1.4677 \%$ \\
\hline & Ac eczema & $1.308 \%$ & $1.119 \%$ & $0.47994 \%$ & $0.3017 \%$ & $0.25747 \%$ & $0.9331 \%$ & $0.7674 \%$ & $0.2112 \%$ \\
\hline \multirow[t]{2}{*}{7} & Chr eczema & $0.382 \%$ & $0.869 \%$ & $0.34805 \%$ & $0.2047 \%$ & $0.47952 \%$ & $1.6346 \%$ & $0.0494 \%$ & 1. $4763 \%$ \\
\hline & Ac eczema & $0.047 \%$ & $0.046 \%$ & $0.00638 \%$ & $0.0107 \%$ & $0.0127 \%$ & $0.0160 \%$ & $0.0690 \%$ & $0.1836 \%$ \\
\hline \multirow[t]{2}{*}{8} & Chr eczema & $0.118 \%$ & $0.884 \%$ & $0.37876 \%$ & $0.0000 \%$ & $0.0000 \%$ & $0.3121 \%$ & $0.0030 \%$ & $0.0000 \%$ \\
\hline & Ac eczema & $0.021 \%$ & $0.060 \%$ & $0.01825 \%$ & $0.0250 \%$ & $0.0000 \%$ & $0.3204 \%$ & $10.5497 \%$ & $0.0000 \%$ \\
\hline \multirow[t]{2}{*}{9} & Chr eczema & $0.148 \%$ & $0.325 \%$ & $0.22387 \%$ & ---- & $0.16626 \%$ & $0.2631 \%$ & $0.1423 \%$ & ----- \\
\hline & Ac eczema & $0.027 \%$ & $0.169 \%$ & $0.0000 \%$ & $0.0000 \%$ & $0.0000 \%$ & $0.0333 \%$ & $0.1206 \%$ & $2.0736 \%$ \\
\hline \multirow[t]{2}{*}{10} & Chr eczema & $0.389 \%$ & $0.248 \%$ & $0.86027 \%$ & $0.1510 \%$ & $0.17505 \%$ & $0.2001 \%$ & $0.0967 \%$ & $1.2447 \%$ \\
\hline & Ac eczema & $0.013 \%$ & $0.713 \%$ & $1.59446 \%$ & $0.0032 \%$ & $0.0000 \%$ & $0.0911 \%$ & $0.1775 \%$ & $0.0000 \%$ \\
\hline \multirow[t]{2}{*}{11} & Chr eczema & $0.0000 \%$ & $0.197 \%$ & $0.0000 \%$ & $0.0000 \%$ & $0.0000 \%$ & $0.1429 \%$ & $0.0000 \%$ & $1.9661 \%$ \\
\hline & Ac eczema & $0.319 \%$ & $0.319 \%$ & $0.02268 \%$ & $0.0000 \%$ & $0.0000 \%$ & $0.1357 \%$ & $0.0143 \%$ & $3.1056 \%$ \\
\hline \multirow[t]{2}{*}{12} & Chr eczema & $0.000 \%$ & $0.020 \%$ & $0.48917 \%$ & $0.0000 \%$ & $0.0000 \%$ & $0.1172 \%$ & $0.1371 \%$ & $1.1221 \%$ \\
\hline & Ac eczema & $1.773 \%$ & $0.438 \%$ & $1.64413 \%$ & $0.0000 \%$ & $0.0000 \%$ & $0.1204 \%$ & $0.2050 \%$ & $0.0000 \%$ \\
\hline \multirow[t]{2}{*}{13} & Chr eczema & $0.035 \%$ & $0.080 \%$ & $0.04448 \%$ & $0.0000 \%$ & $0.18823 \%$ & $0.1052 \%$ & $0.0738 \%$ & $1.0274 \%$ \\
\hline & Ac eczema & $0.215 \%$ & $0.601 \%$ & $0.06427 \%$ & $0.0215 \%$ & $0.0000 \%$ & $0.1374 \%$ & $0.2862 \%$ & $0.6652 \%$ \\
\hline \multirow[t]{2}{*}{14} & Chr eczema & $0.536 \%$ & $0.204 \%$ & $0.09632 \%$ & $0.0412 \%$ & $0.10718 \%$ & $0.1065 \%$ & $0.1261 \%$ & $0.2513 \%$ \\
\hline & Ac eczema & $0.068 \%$ & $0.265 \%$ & $0.04844 \%$ & $0.1167 \%$ & $0.02419 \%$ & $0.0696 \%$ & $0.0334 \%$ & $0.0511 \%$ \\
\hline \multirow[t]{3}{*}{15} & Chr eczema & $0.519 \%$ & $0.221 \%$ & $0.28177 \%$ & $0.0126 \%$ & $1.29387 \%$ & $0.5373 \%$ & $0.0000 \%$ & $2.2824 \%$ \\
\hline & Ac eczema & $0.001 \%$ & $0.136 \%$ & $0.14102 \%$ & $0.0046 \%$ & $0.0000 \%$ & $0.0301 \%$ & $0.0000 \%$ & $0.0000 \%$ \\
\hline & Chr eczema & $0.286 \%$ & $0.318 \%$ & $0.10705 \%$ & $0.1545 \%$ & $0.03365 \%$ & $0.3748 \%$ & $0.1230 \%$ & $1.2960 \%$ \\
\hline \multirow[t]{2}{*}{16} & Ac eczema & $0.116 \%$ & $0.027 \%$ & $0.02668 \%$ & $0.0000 \%$ & $0.0000 \%$ & $0.0937 \%$ & $0.0760 \%$ & $2.8711 \%$ \\
\hline & Chr eczema & $0.187 \%$ & $0.228 \%$ & $0.04855 \%$ & $0.0207 \%$ & $0.0000 \%$ & $1.0891 \%$ & $0.0000 \%$ & $0.0000 \%$ \\
\hline \multirow[t]{2}{*}{17} & Ac eczema & $0.133 \%$ & $2.673 \%$ & $0.0000 \%$ & $0.0223 \%$ & $0.02783 \%$ & $0.1344 \%$ & $0.0274 \%$ & $0.4137 \%$ \\
\hline & Chr eczema & $0.498 \%$ & $0.393 \%$ & $0.37860 \%$ & $0.2112 \%$ & $0.16018 \%$ & $0.4355 \%$ & $0.2590 \%$ & $0.5967 \%$ \\
\hline \multirow[t]{2}{*}{18} & Ac eczema & $0.087 \%$ & $0.144 \%$ & $0.02491 \%$ & $0.0089 \%$ & $0.00620 \%$ & $0.0757 \%$ & $0.0998 \%$ & $0.0000 \%$ \\
\hline & Chr eczema & $0.367 \%$ & $0.940 \%$ & $0.07814 \%$ & $0.0082 \%$ & $0.00712 \%$ & $0.1361 \%$ & $0.1099 \%$ & $2.3796 \%$ \\
\hline \multirow[t]{2}{*}{19} & Ac eczema & $0.000 \%$ & $0.469 \%$ & $0.00000 \%$ & $0.0217 \%$ & $0.0000 \%$ & $0.0673 \%$ & ----- & $1.5081 \%$ \\
\hline & Chr eczema & $0.213 \%$ & $1.941 \%$ & $0.27333 \%$ & $0.0610 \%$ & $0.01930 \%$ & $0.0841 \%$ & $0.0684 \%$ & $2.8617 \%$ \\
\hline 20 & Ac eczema & $0.082 \%$ & $0.108 \%$ & $0.01537 \%$ & $0.0490 \%$ & $0.01103 \%$ & $0.0257 \%$ & $0.0154 \%$ & $0.1261 \%$ \\
\hline
\end{tabular}

Source: Data collected by the author.; N: Number of cases; INF- $\gamma$ : Interferon gamma; TNF- $\alpha$ : Tumor necrosis factor alpha; IL: Interleukin. Chr eczema: Chronic eczema; Ac eczema: Acute eczema. 


\begin{tabular}{|c|c|c|c|c|c|c|c|c|c|c|}
\hline \multirow{3}{*}{ Cytokine } & \multicolumn{10}{|c|}{ Type of eczema } \\
\hline & \multicolumn{5}{|c|}{ Chronic } & \multicolumn{5}{|c|}{ Acute } \\
\hline & $\mathbf{N}$ & Minimum & Maximum & Median & $\mathrm{CV}$ & $\mathbf{N}$ & Minimum & Maximum & Median & $\mathrm{CV}$ \\
\hline IFN- $\gamma$ & 20 & 0.00 & 0.74 & 0.33 & 0.73 & 20 & 0.00 & 3.95 & 0.12 & 1.78 \\
\hline IL-2 & 20 & 0.02 & 1.45 & 0.32 & 0.85 & 20 & 0.03 & 2.67 & 0.40 & 1.10 \\
\hline IL-4 & 20 & 0.00 & 3.14 & 0.28 & 1.51 & 20 & 0.00 & 3.59 & 0.04 & 1.97 \\
\hline IL-10 & 19 & 0.00 & 0.47 & 0.01 & 1.53 & 20 & 0.00 & 0.30 & 0.01 & 2.23 \\
\hline IL-13 & 20 & 0.00 & 1.29 & 0.08 & 1.64 & 20 & 0.00 & 0.84 & 0.00 & 3.01 \\
\hline IL-17 & 20 & 0.08 & 1.17 & 0.19 & 0.97 & 20 & 0.02 & 5.69 & 0.13 & 2.55 \\
\hline IL-23 & 20 & 0.00 & 0.41 & 0.09 & 1.05 & 19 & 0.00 & 10.55 & 0.10 & 3.33 \\
\hline TNF- $\alpha$ & 19 & 0.00 & 2.86 & 0.97 & 0.94 & 20 & 0.00 & 3.11 & 0.20 & 1.34 \\
\hline
\end{tabular}

Source: Data collected by the author. N: Number of cases; CV: Coefficient of variation.

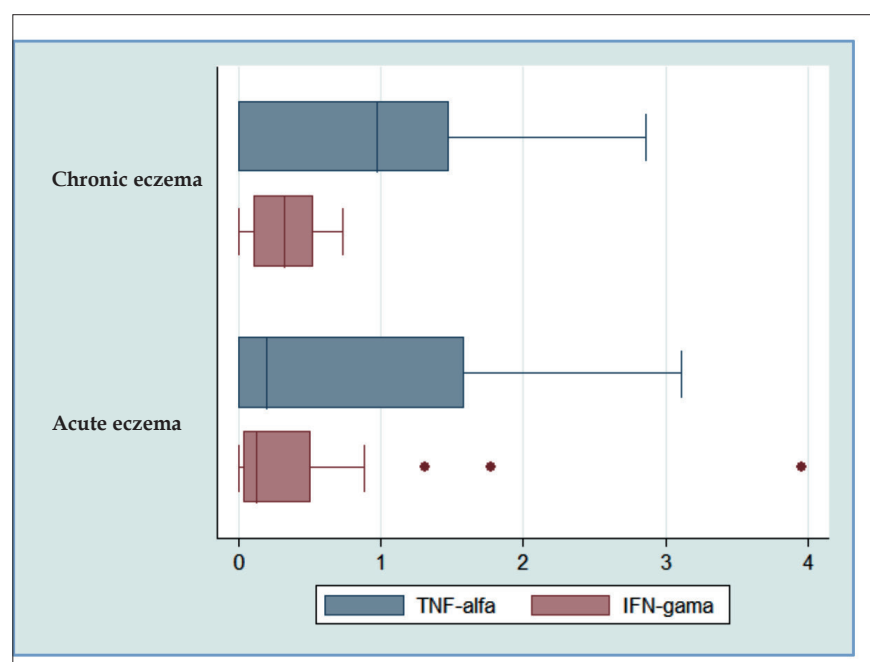

SOURCE: Data collected by the author

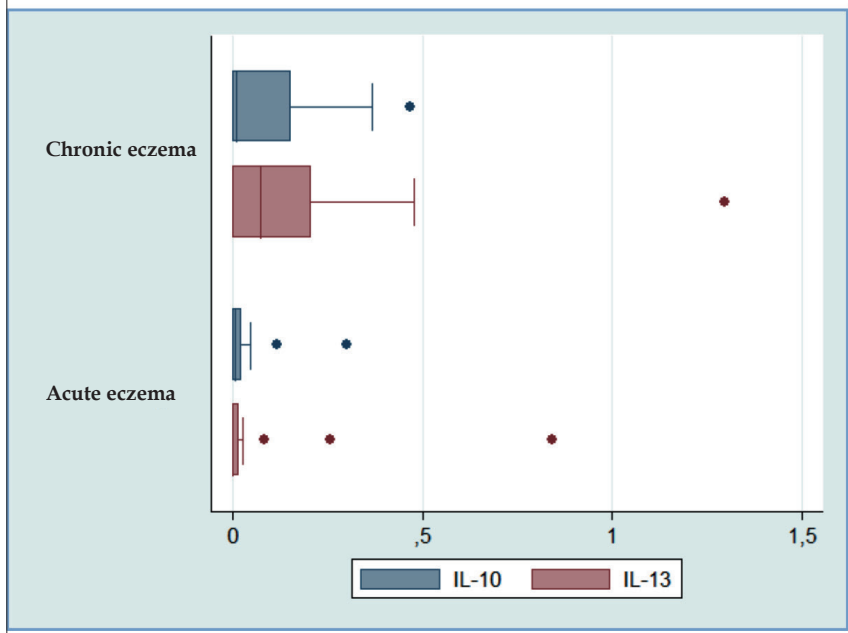

Source: Data collected by the author

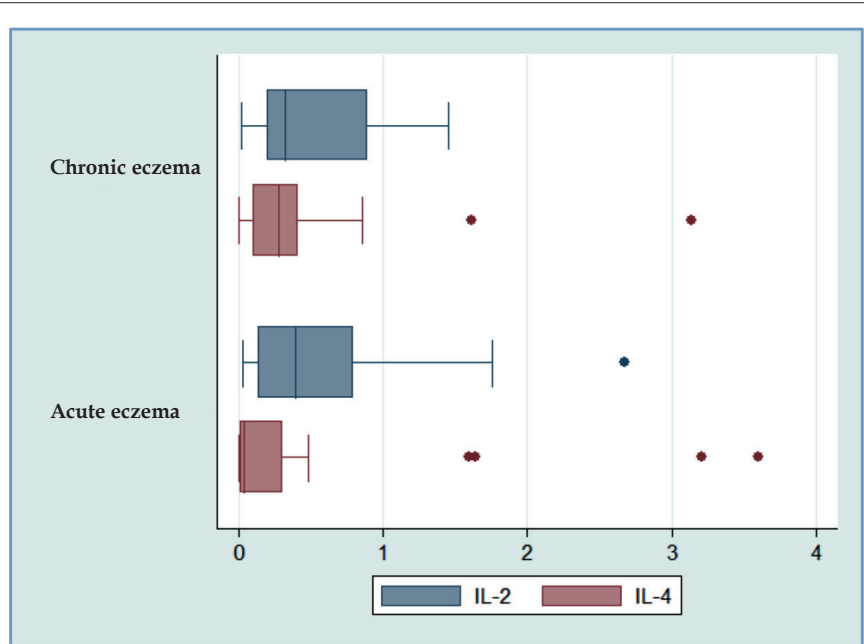

SourcE: Data collected by the author

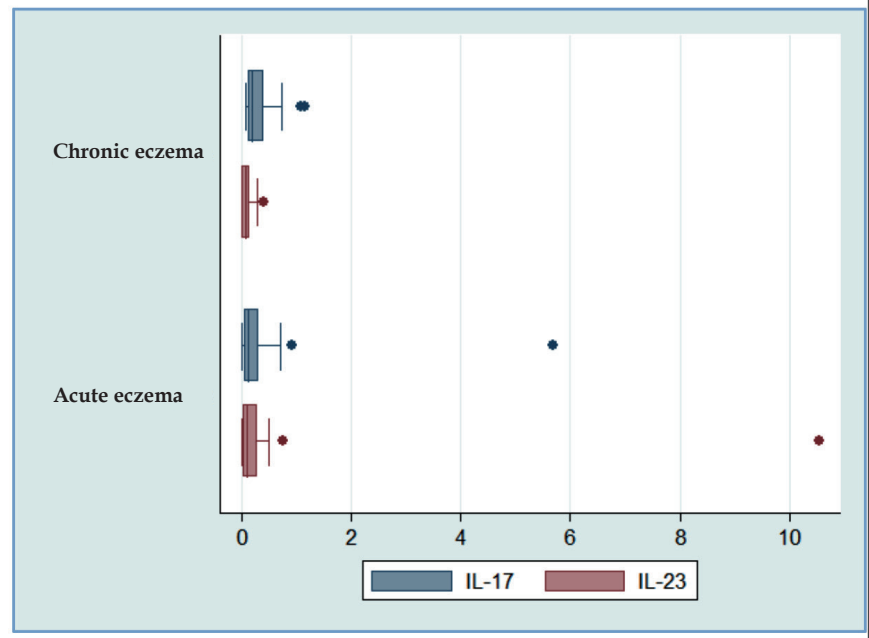

Source: Data collected by the author

FIGURE 2: Boxplots. A - TNF- $\alpha$ and IFN- $\gamma$, higher prevalence in chronic eczema; TNF- $\alpha$, higher heterogeneity of the values in acute eczema, with the absence of atypical values; IFN- $\gamma$, higher heterogeneity of the values in acute eczema, with three atypical values. B - IL-2, higher prevalence and heterogeneity of the values in acute eczema, with one atypical value; IL-4, higher prevalence in chronic eczema and higher heterogeneity of the values in acute eczema, with four atypical values. C - IL-10, similar prevalence in acute and chronic eczemas and higher heterogeneity of the values in acute eczema, with two atypical values; IL-13, higher prevalence in chronic eczema and higher heterogeneity of the values in acute eczema, with three atypical values. D - IL-17, higher prevalence in chronic eczema and higher heterogeneity of the values in acute eczema, with two atypical values; IL-23, higher prevalence and heterogeneity of the values in acute eczema, with two atypical values 
amounts after 24 hours. ${ }^{34} \mathrm{IL}-2$ is produced by CD4+ T-cells and acts on the cells that produce it, i.e., it acts as an autocrine growth factor. It stimulates growth, differentiation and proliferation of $\mathrm{T}$ and B lymphocytes (antibody formation) and NK cells (favoring their cytolytic activity) and is responsible for the clonal expansion of lymphocytes specific to the antigen that is being presented. ${ }^{35}$

Our data showed a higher prevalence of IFN- $\gamma$, IL-4 and IL13 in chronic eczema, which is frequently triggered by re-exposure to Ni2+. These prevalences were statistically significant for IL-4 and IL-13; which did not apply to IFN- $\gamma$. In our study, biopsies in acute eczemas were collected 48 hours after provocation with NiSO4, from a skin that was never in contact with the antigen, and IFN- $\gamma$, IL-4 and IL-13 had low prevalences, probably because they would need more time to be produced. The literature demonstrates that, in stimulated mononuclear cell cultures from the peripheral blood of patients allergic to Ni2+, increased levels of IL- 4 were produced after 72 hours. ${ }^{34} \mathrm{~A}$ study with skin of mice with chronic contact hypersensitivity, demonstrated increased accumulation of IFN- $\gamma$-producing resident memory antigen-specific CD8+ T-cells. . $^{16,36,37}$ In allergic individuals, there is a proliferative $\mathrm{Ni2}+$-specific $\mathrm{T}$-cell response in contrast to non-allergic patients, and also the production of IFN- $\gamma$, IL-4 and IL-13, indicating a mixed Th1 and Th2 cytokine pattern in individuals allergic to $\mathrm{Ni} 2+.34,37$

IL-13 is a cytokine similar to IL-4, and the cell receptor that recognizes IL-13 can bind IL-4 to IL-13 with high affinity. Therefore, these two interleukins share biological effects. ${ }^{38}$ The number of IL-4-producing cells correlates with the number of IL-13-producing cells, suggesting a synergy between Th2-type cytokines. ${ }^{34}$

Our data demonstrate that IL-10 had a similar prevalence in acute and chronic eczemas. However, these prevalences were very low in both eczemas. Therefore, the lack of negative regulation of proinflammatory cytokines favored the persistence of the cutaneous inflammatory reaction in chronic eczema frequently triggered by Ni2+. Yet, it was not possible to establish a statistical difference of the prevalences in chronic and acute eczemas and, although the prevalences were very close, due to the heterogeneity of the values we cannot statistically affirm that these prevalences were equal. IL10 was identified as a potent anti-inflammatory cytokine produced

TABLE 3: Comparison of the medians of eight cytokines (IFN- $\gamma$, IL-2, IL-4, IL-10, IL-13, IL-17, IL-23 and TNF- $\alpha$ ) in chronic and acute eczemas triggered by nickel - 2013 to 2016

\begin{tabular}{lc} 
Cytokine & $p$-value \\
\hline IFN- $\gamma$ & 0.5338 \\
IL-2 & 0.8924 \\
IL-4 & 0.0303 \\
IL-10 & 0.3546 \\
IL-13 & 0.0336 \\
IL-17 & 0.0884 \\
IL-23 & 0.2375 \\
TNF- $\alpha$ & 0.4775 \\
\hline
\end{tabular}

Source: Data collected by the author. $p$-value $<0.05$ there was difference between the medians. by Tregs cells, negatively regulating the expression of necessary molecules for adequate antigen presentation and controlling the activity of $\mathrm{CD} 8+$ effectors. It shows a regulatory activity in the sensitization and elicitation phases of $\mathrm{ACD}$, contributing for the control of the immune response to Ni2+. ${ }^{14,39,40} \mathrm{Ni2}+$-specific Tregs cell clones from non-allergic individuals produce higher levels of IL-10 than those from allergic patients. ${ }^{7}$

Our data demonstrate that IL-17 was more prevalent in chronic eczema than in acute eczema. Thus, being a proinflammatory mediator, chronic lesions are frequently exacerbated, resulting in an intense and sustained cutaneous inflammatory reaction. Nevertheless, this higher prevalence in chronic eczema was not statistically significant. The literature demonstrates that, as with IFN- $\gamma$, IL-17 in involved in the regulation of cutaneous allergic conditions and inflammation in ACD is prone to be triggered and sustained by the proinflammatory effects of IL-17A/IL-17F and other cytokines produced by Th17/Tc17 antigen-specific T-cells. . $8,37,41,42^{-1}$

Immunohistochemistry performed in skin biopsies after 24 , 48,72 and 96 hours of a positive CT to NiSO4, showed that, after 24 hours, IL-17 did not increase significantly, but did show an increase after 48 and 72 hours and also numerous intraepidermal IL-17+ cells were seen after 96 hours, mainly distributed on the area of intense tissue damage (epidermal spongiosis and microvesiculation). ${ }^{33,37,41}$

Our data showed positivity for IL-23, with a higher prevalence in acute eczema when compared to chronic eczema. Nonetheless, this prevalence was not statistically significant. IL-23 is produced by macrophages and DCs and is important for the development of the effector activity of Th17 cells, promoting the expression and maintenance of IL-17 and TNF- $\alpha$ production. . $19,42,43^{\text {Thus, }}$ it acts on the development of the inflammation in the dermis and acanthosis in the epidermis that occur in ACD. This was demonstrated in IL-23-defficient mice, who had an impaired contact hypersensitivity reaction. ${ }^{42}$

\section{CONCLUSION}

With the analysis of the cytokines TNF- $\alpha$, INF- $\gamma$, IL-2, IL-4, IL-10, IL-13, IL-17 and IL-23 in chronic and acute eczemas of Ni2+ACD patients, we observed the presence of a pattern of mixed T-cell subtypes cytokines (Th/Tc), suggesting that the responses are expressed simultaneously. TNF- $\alpha$, IFN- $\gamma$, IL-4, IL-13 and IL-17 had higher prevalence in chronic eczema; IL-2 and IL-23 in acute eczema and IL-10 had similar prevalence in both eczemas. We observed that the higher prevalence of IL-4 and IL-13 in chronic eczema was statistically significant, even though it was not possible to establish statistical significance of the higher prevalence of IFN- $\gamma$, IL-17 and TNF- $\alpha$ in chronic eczema and of IL-2 and IL-23 in acute eczema. And, due to the heterogeneity of the values, we cannot state that there the prevalences for IL-10 were statistically equal.

However, more studies are needed for a broader understanding of the cytokine profile in Ni2+ ACD, what could lead to new therapeutic approaches. 


\section{REFERENCES}

1. Hennino A, Vocanson M, Chavagnac C, Saint-Mezard P, Dubois B, Kaiserlian D, et al. Fisiopatologia da dermatite de contato alérgica: papel das células T CD8 efetoras e das células T CD4 regulatórias. An Bras Dermatol. 2005;80:335-47.

2. Yucesoy B, Talzhanov Y, Barmada MM, Johson VJ, Kashon ML, Baron E, et al. Association of MHC region SNPs with irritant susceptibility in healthcare workers. J Immunotoxicol. 2016;13:738-44.

3. Dittmar D, Schuttelaar ML. Immunology and genetics of tumour necrosis factor in allergic contact dermatitis. Contact Dermatitis. 2017;76:257-71

4. Natsuaki Y, Kabashima K. Inducible lymphoid clusters, iSALTs, in contact dermatitis: a new concept of acquired cutaneous immune responses. Med Mol Morphol. 2016;49:127-32.

5. Fallahi P, Ruffilli I. Contact dermatitis and interferon- $\gamma$ dependent chemokines. Clin Ter. 2016;167:e112-6.

6. Thyssen JP, Menné T. Metal allergy--a review on exposures, penetration, genetics, prevalence, and clinical implications. Chem Res Toxicol. 2010;23:309-18.

7. Kimber I, Travis MA, Martin SF, Dearman RJ. Immunoregulation of skin sensitization and regulatory T cells. Contact Dermatitis. 2012;67:179-83.

8. Honda T, Egawa G, Grabbe S, Kabashima K. Update of immune events in the murine contact hypersensitivity model: toward the understanding of allergic contact dermatitis. J Invest Dermatol. 2013;133:303-15.

9. Ashrin MN, Arakaki R, Yamada A, Kondo T, Kurosawa M, Kudo Y, et al. A critical role for thymic stromal lymphopoietin in nickel-induced allergy in mice. J Immunol. 2014; 192:4025-31.

10. Nasorri F, Sebastiani S, Mariani V, De Pità O, Puddu P, Girolomoni G, et al. Activation of nickel-specific CD4+ T lymphocytes in the absence of professional antigen-presenting cells. J Invest Dermatol. 2002;118:172-9.

11. Larsen JM, Bonefeld CM, Poulsen SS, Geisler C, Skov L. IL-23 and T(H)17mediated inflammation in human allergic contact dermatitis. J Allergy Clin Immunol. 2009;123:486-92.

12. Vocanson M, Hennino A, Rozières A, Poyet G, Nicolas JF. Effector and regulatory mechanisms in allergic contact dermatitis. Allergy. 2009;64:1699-714.

13. Kaplan DH, Igyártó BZ, Gaspari AA. Early immune events in the induction of allergic contact dermatitis. Nat Rev Immunol. 2012;12:114-24.

14. Kim HS, Jang JH, Lee MB, Jung ID, Kim YM, Park YM, et al. A novel IL-10producing innate lymphoid cells (ILC10) in a contact hypersensitivity mouse model. BMB Rep. 2016:49:293-6

15. Kimber I, Basketter DA, Gerberick GF, Dearman RJ. Allergic contact dermatitis. Int Immunopharmacol. 2002;2:201-11.

16. Schmidt M, Goebeler M. Immunology of metal allergies. J Dtsch Dermatol Ges. 2015:13:653-60

17. Weaver CT, Hatton RD, Mangan PR, Harrington LE. IL-17 family cytokines and the expanding diversity of effector T cell lineages. Annu Rev Immunol. 2007;25:821-52.

18. Hofmann MA, Kiecker $F$, Zuberbier T. A systematic review of the role of interleukin-17 and the interleukin-20 family in inflammatory allergic skin diseases. Curr Opin Allergy Clin Immunol. 2016;16:451-7.

19. Bai S, Zhang Z, Hou S, Liu X. Influence of different types of contact hypersensitivity on imiquimod-induced psoriasis-like inflammation in mice. Mol Med Rep. 2016;14:671-80.

20. Duarte I, Lazzarini R, Buense R. Interference of the position of substances in an epicutaneous patch test battery with the occurrence of false-positive results. Am $J$ Contact Dermatitis. 2002;13:125-32.

21. Sampaio SAP, Rivitti EA. Erupções eczematosas. In: Sampaio SAP, Rivitti EA editores. Dermatologia. 3rd ed. São Paulo: Artes Médicas; 2007. p.189-208.

22. Lachapelle JM, Maibach HI. Patch testing and prick testing: a practical guide official publication of the ICDRG. 2nd ed. Berlin: Spring-Verlag. 2009.

23. Sabattini E, Bisgaard K, Ascani S, Poggi S, Piccioli M, Ceccarelli C, et al. The EnVision++ system: a new immunohistochemical method for diagnostics and research. Critical comparison with the APAAP, ChemMate, CSA, LABC, and SABC techniques. J Clin Pathol. 1998;51:506-11.
24. Carvalho AL. Avaliação da glicoproteína CRISP-3 como potencial biomarcador no prognóstico do câncer de próstata [dissertação]. Jataí (G0): Universidade Federal de Goiás; 2016.

25. Shapiro SS, Wilk MB. An analysis of variance test for normality (complete samples). Biometrika. 1965;52:591-611.

26. Conover WJ. Practical nonparametric statistics. 3rd ed. New York: Wiley; 1998.

27. Martins GA, Domingues 0. Estatística geral e aplicada. 4th ed. São Paulo: Atlas 2011.

28. Borg L, Christensen JM, Kristiansen J, Nielsen NH, Menné T, Poulsen LK. Nickelinduced cytokine production from mononuclear cells in nickel-sensitive individuals and controls. Cytokine profiles in nickel-sensitive individuals with nickel allergyrelated hand eczema before and after nickel challenge. Arch Dermatol Res. 2000;292:285-91.

29. Falsafi-Amin H, Holst M, Lundeberg L. Early expression of interleukin-2 mRNA by peripheral blood mononuclear cells isolated from nickel-allergic subjects and subsequently exposed to nickel in vitro. Immunopharmacol Immunotoxicol. 2008:30:227-34.

30. Falsafi-Amin H, Lundeberg L, Bakhiet M, Nordlind K. Early DNA synthesis and cytokine expression in the nickel activation of peripheral blood mononuclear cells in nickel-allergic subjects. Int Arch Allergy Immunol. 2000;123:170-6.

31. Carlsen BC, Andersen KE, Menné T, Johansen JD. Patients with multiple contact allergies: a review. Contact Dermatitis. 2008;58:1-8.

32. Watanabe $\mathrm{H}$, Gaide $\mathrm{O}$, Pétrilli V, Martinon F, Contassot E, Roques S, et al. Activation of the IL-1 $\beta$-processing inflammasome is involved in contact hypersensitivity. $J$ Invest Dermatol. 2007:127:1956-63.

33. Wang C, Yuan J, Wu HX, Chang Y, Wang QT, Wu YJ, et al. Total glucosides of paeony inhibit the inflammatory responses of mice with allergic contact dermatitis by restoring the balanced secretion of pro-/anti-inflammatory cytokines. Int Immunopharmacol. 2015;24:325-34

34. Jakobson E, Masjedi K, Ahlborg N, Lundeberg L, Karlberg AT, Scheynius A Cytokine production in nickel-sensitized individuals analysed with enzymelinked immunospot assay: possible implication for diagnosis. $\mathrm{Br} \mathrm{J}$ Dermatol. 2002;147:442-9.

35. Mesquita Júnior D, Araújo JAP, Catelan TTT, Souza AWS, Cruvinel WM, Andrade LEC, et al. Immune System - Part II Basis of the immunological response mediated by T and B lymphocytes. Rev Bras Reumatol. 2010;50:552-80.

36. Gimenez-Rivera VA, Siebenhaar F, Zimmermann C, Siiskonen H, Metz M, Maure M. Mast Cells Limit the Exacerbation of Chronic Allergic Contact Dermatitis in Response to Repeated Allergen Exposure. J Immunol. 2016;197:4240-6.

37. Schmidt JD, Ahlström MG, Johasen JD, Dyring-Andersen B, Agerbeck C, Nielsen MM, et al. Rapid allergen-induced interleukin-17 and interferon- $\gamma$ secretion by skin-resident memory CD8+ T cells. Contact Dermatitis. 2017;76:218-27.

38. Abbas AK, Lichtman AH, Pillai S. Imunologia celular e molecular. 6th ed. Rio de Janeiro: Elsevier; 2008

39. Bordignon V, Palamara F, Cordiali-Fei P, Vento A, Aiello A, Picardo M, et al. Nickel, palladium and rhodium induced IFN-gamma and IL-10 production as assessed by in vitro ELISpot-analysis in contact dermatitis patients. BMC Immunol. 2008;9:19.

40. Dolch A, Kunz S, Dorn B, Roers A, Martin SF, Jakob T. Contact allergens induce CD8 + T cell-derived interleukin 10 that appears dispensable for regulation of contact hypersensitivity. Exp Dermatol. 2017;26:449-51.

41. Bonefeld CM, Geisler $\mathrm{C}$. The role of innate lymphoid cells in healthy and inflamed skin. Immunol Lett. 2016;179:25-8.

42. Heo WI, Lee KE, Hong JY, Kim MN, Oh MS, Kim YS, et al. The role of interleukin-17 in mouse models of atopic dermatitis and contact dermatitis. Clin Exp Dermatol. 2015;40:665-71.

43. $\quad$ Langrish CL, Chen Y, Blumenschein WM, Mattson J, Basham B, Sedgwick JD, et al. IL-23 pathogenic T-cell population induces autoimmune inflammation. J Exp Med. 2005;201:233-40.

Statistical analysis, Approval of the final version of the manuscript, Conception and planning of the study, Elaboration and writing of the manuscript, Obtaining, analyzing and interpreting the data, Intellectual participation in propaedeutic and/or therapeutic conduct of the cases studied, Critical review of the literature, Critical review of the manuscript Vitor Manoel Silva dos Reis (iD) ORCID 0000-0001-5705-4104

Approval of the final version of the manuscript, Conception and planning of the study, Obtaining, analyzing and interpreting the data, Effective participation in research orientation, Intellectual participation in propaedeutic and/or therapeutic conduct of the cases studied, Critical review of the manuscript

How to cite this article: Silvestre MC, Reis VMS. Evaluation of the profile of inflammatory cytokines, through immunohistochemistry, in patients skin with allergic contact dermatitis to nickel in the acute and chronic phases. An Bras Dermatol. 2018;93(6):829-35. 